ISSN 2333-8385

\title{
From Wintrobe to the XXI century. A Story of Inspiration and Effort
}

Review Article

E. Urrechaga ${ }^{1 *}$, J.J.M.L. Hoffmann ${ }^{2}$ J.F. Escanero ${ }^{3}$

${ }^{1}$ HematologyLaboratory, Hospital Galdakao - Usansolo, 48960 Galdakao, Vizcaya, Spain.

${ }^{2}$ Medical \& Scientific Affairs, Abbott Diagnostics, Abbott GmbH \& Co. KG, Wiesbaden-Delkenheim 65205 Germany.

${ }^{3}$ Department of Pharmacology and Physiology, University of Zaragoza, 50008 Zaragoza, Spain.

\begin{abstract}
In 2014 we are celebrating the 80th anniversary of the Maxwell Myer Wintrobe's pioneer works, one of the most important contributions in Clinical Laboratory and Medicine. Red cell indices continue to provide an essential support to the diagnosis and classification of anemia.

The erythrocyte indices mean cell volume, mean cell hemoglobin concentration, mean cell hemoglobin are called the Wintrobe indices. Hematology automation has progressed steadily since Wallace Coulter first applied electrical impedance technology to counting red cells and white cells.

Technological advances being incorporated into hematology analyzers since then are now allowing the access to more cellular information than was ever available before through a "simple routine CBC".

Current research is beginning to demonstrate that this information also has great potential to identify cellular changes that typically occur in several important medical conditions-bringing us all one step closer to using hematology analyzers as more than simple cell counters, but instead as powerful tools for the management of any medical condition that impacts the biology of blood cells.

There are increasing amounts of data provided, which require specialist knowledge to interpret as well as understand the limitations in the measurement of the parameter. Both laboratory scientists and clinicians need to keep up to date with new parameters and methods in hematology, implying a stronger collaboration between them to improve clinical decision making.
\end{abstract}

Keywords: Anemia; Erythrocyte Indices; Red Cells; Hematology Analyzers.

\section{*Corresponding Author:}

E. Urrechaga,

HematologyLaboratory, Hospital Galdakao - Usansolo, 48960 Galdakao, Vizcaya, Spain.

E-mail: eloisa.urrechagaigartua@osakidetza.net

Received: May 13, 2014

Accepted: June 07, 2014

Published: June 09, 2014

Citation: E. Urrechaga, J.J.M.L. Hoffmann, J.F. Escanero. (2014) . From Wintrobe to the XXI century. A Story of Inspiration and Effort, Int J Translation Community Dis, 02(04), 37-41. doi: http://dx.doi. org $/ 10.19070 / 2333-8385-140007$

Copyright: E. Urrechaga ${ }^{\circ} 2014$ This is an open-access article distributed under the terms of the Creative Commons Attribution License, which permits unrestricted use, distribution and reproduction in any medium, provided the original author and source are credited.

\section{Remembering The History}

\section{MMWintrobe the pioneer}

In 2014 we are celebrating the $80^{\text {th }}$ anniversary of Maxwell Myer Wintrobe's pioneer publications, one of the most important contributions in Clinical and Laboratory Medicine. Red cell indices, widely known as Wintrobe's indices, continue to provide an essential support to the diagnosis and classification of anemia.
From the measurements of the average volume and Hemoglobin $(\mathrm{Hb})$ concentration of erythrocytes, the underlying etiology of anemia was brilliantly unveiled [1-4].

Anemia is a disease itself, but it is often symptomatic of other illness; every clinician deals with anemia in daily practice, taking into account that concomitant anemia makes the prognosis of the underlying disease worse for those patients.

His textbook Clinical Hematology, first published in 1942 and now in its $13^{\text {th }}$ edition [5], remains a prototype of excellence and for many years stood alone as the premier text in the field. He had written and edited the first six editions by himself, though always depending on the critical peer review of his talented colleagues at Utah University, with his wife Becky, as he said his severest and most helpful critic [6].

Hematology, the Blossoming of a Science: A Story of Inspiration and Effort was published on 1985, shortly before his demise [7]. Writing this book partially as his memoirs, partially as history, Wintrobe realized that he could never cover the lives of all who had contributed to what he called "the Golden Age of Hematology".

Wintrobe's methods were based on manual measurements of hemoglobin, hematocrit and erythrocyte count. Reading his articles published the 30's [1-4], his concern with the accuracy of the methods and the reliability of the measurements become evident. First, he proposed a classification of anemia, based on the new 
indices. Then he brilliantly postulated the link with red cell morphology to deduce the real etiology of each type of anemia.

The erythrocyte indices mean corpuscular volume (MCV), mean corpuscular hemoglobin concentration (MCHC) and mean corpuscular hemoglobin $(\mathrm{MCH})$ were derived from precisely measured values of $\mathrm{Hb}$, hematocrit and red cell count are called the Wintrobe indices, in honor of Wintrobe's invention [8].

The complete blood count (CBC; also called full blood count or hemogram, depending on geographical region) is one of the most frequently requested tests by clinicians and the indices are still applied for classifying anemia. The analysis nowadays is totally automated and correct interpretation of the results requires reuniting knowledge about the characteristics of the measurement equipment and the clinical meaning of the results [9].

\section{The birth of automation}

The first attempt in automation of blood cell counts was the introduction of the Coulter Principle. While under contract to the United States Navy, Wallace H. Coulter developed a technology for counting and sizing particles using impedance measurements in the late 1940s, though a patent was not awarded until October 20, 1953. The technology was principally developed for counting blood cells quickly by measuring the changes in electrical conductance when cells suspended in a conductive fluid pass through a small orifice. Presently, the automated cell counters incorporate this technology, which is referred to as the Coulter Principle.

Using electronic count and pulse height analyzer circuits, the number of particles and volume of each particle passing through the aperture can be measured. When the volume of liquid passing through the aperture can be precisely controlled and measured, the cell concentration in the blood sample can also be determined A typical measurement using Coulter type instruments takes less than a minute, as counting and sizing rates of up to 10,000 particles per second are well possible. The precision of the size measurements is generally better than $1 \%[10]$.

Hematology automation has progressed steadily since Wallace Coulter first impedance his technology to blood. By the 1980s, most hematology laboratories were reporting out a 7-parameter CBC and three-part white blood cell (WBC) differential, all obtained from a single aspiration of a small volume of blood in a stand-alone, bench-top instrument. Eventually, this process was upgraded even further when it became possible to obtain these results without uncapping the sample.

An often overlooked fact is that individual red cell volume determination is dependent on the technology used by a specific hematology analyzers and that hematocrit value is calculated from the measured MCV. The only red cell index that is consistent throughout all hematology analyzers is $\mathrm{MCH}$, which is derived from precisely measured values of $\mathrm{Hb}$ and red cell count [8].

In the 90's the analyzers became capable of quantifying the heterogeneity in red cell volume, which resulted in the red cell distribution width (RDW), which is adding remarkably useful information to MCV. MCV is the mean of the volumes of all erythrocytes, whereas RDW refers to the dispersion of cells with different volumes present in the whole population, so the contribution of marginally sized subsets to the calculated mean value can be assessed [11].
Although RDW is generally expressed as a coefficient of variation of the distributions of erythrocyte volume, some hematology analyzers calculate RDW from the direct measurement of the width of the distribution [12].

\section{Technological Progress}

\section{Erythrocytes}

Optical technology combined with flow cytometry for measuring physical and chemical characteristics of cells constituted another breakthrough in automated hematology analyzers.

The basic purpose of the optics bench in a flow cytometer is to detect light scattered by cells as they pass through a flow cell illuminated by a light beam, most often a laser beam. The scattered light harbors information on the cell size, its surface and internal structures. When scattered light is measured under different angles, these data can be combined in multiple dimensions, allowing discrimination of different cell types [13].

Optical flow cytometric technology for RBC measurement was first made available by the then Technicon Company in their $\mathrm{H}^{*}$ series of instruments, later followed by the Advia ${ }^{\circledR}$ hematology analyzers (Bayer Diagnostics, presently Siemens Healthcare Diagnostics, Deerfield, IL, USA). This optical technology enables measuring, simultaneous and independently, the cellular $\mathrm{Hb}$ concentration of individual erythrocytes as well as their volume, derived from light scatter by isovolumetrically sphered RBC according to the Mie theory $[14,15]$. Mie theory describes the mathematics of light diffraction by spherical objects, in this case the red cells, which are transformed into isovolumetric spheres. When using monochromatic laser light, diffraction is only a function of the size and the refractive index of the object, which in erythrocytes is directly related to the cell's $\mathrm{Hb}$ concentration.

In the red cell/platelet channel, red cells are converted to spheres. Using Mie theory, low-angle $\left(2^{\circ}-3^{\circ}\right)$ and high-angle $\left(5^{\circ}-15^{\circ}\right)$ light scatter is measured and mathematical models in the software use these scatter signals for calculating the size and cellular hemoglobin concentration (CHC) of individual red cells.

Both measurements can be provided as a 2-dimensional scattergram. In this graph, the volume of individual red cells is plotted on the y-axis, and their intracellular hemoglobin concentration on the $\mathrm{x}$-axis. In addition to a graphical representation, also quantitative data can be derived from these measurements: hypochromic RBC with $\mathrm{CHC}<280 \mathrm{~g} / \mathrm{L}$, hyperchromic RBC with $\mathrm{CHC}>410$ $\mathrm{g} / \mathrm{L}$, microcytic with volume $<60 \mathrm{fL}$ and macrocytic with volume $>120 \mathrm{fL}$

Technicon Instruments was the first manufacturer to offer a complete set of extended RBC parameters in their $\mathrm{H}^{*} 3$ hematology analyzer [16] and this explains why the majority of literature on these parameters was produced using this analyzer and its successors of the Advia series (Siemens Healthcare Diagnostics, Deerfield, IL, USA).

More recently, Abbott (Abbott Diagnostics, Santa ClaraCA, USA) introduced extended RBC parameters on the CELL-DYN Sapphire analyzer. These are calculated from three-dimensional laser light scatter, applying the principles of the Mie theory, which is basically the same as in the Advia analyzers $[17,18]$. 
Over the past years, other manufacturers have started offering extended RBC parameters, although differences in the technology used make it impossible to directly compare the numerical values of RBC parameters derived from different instruments.

Sysmex analyzers XE-5000 and XN-series (Sysmex Corporation, Kobe, Japan) report some RBC extended parameters, the percentages of erythrocyte subsets. In the reticulocyte channel hypochromic and hyperchromic erythrocytes are quantified, but it is important to highlight that is $\mathrm{Hb}$ content, not cellular $\mathrm{Hb}$ concentration, what is reported. Hypochromic red cells by Sysmex are those with an $\mathrm{Hb}$ content less than $17 \mathrm{pg}$, while hyperchromic are those with Hbover 49pg [19].

Because of the relatively long life span of mature erythrocytes, the classical Wintrobe indices reflect the overall erythrocyte production and iron incorporation into $\mathrm{Hb}$ over the last 2-3 months.

As previously mentioned in the 80 s the analyzers were capable to quantify the heterogeneity in distribution of both mean cell volume (RDW) adding a remarkable useful information to MVC. This is not the case for MHC. Calculated from red blood cell count and $\mathrm{Hb}, \mathrm{MCH}$ represents the average.

But different set of numbers can render nearly the same mean. In order to describe mathematically a set two types of measures are necessary centralization measures (more abundant individuals) and of dispersion, giving insight on the heterogeneity of the population.

The percentage of subsets can give complementary information of the contribution of cell with extreme values (hypochromic and hyperchromic cells) to the mean values, $\mathrm{MCH}$. The percentages reflects how $\mathrm{Hb}$ is distributed in the individual cells, in a uniform way or not; if polychromasia is present, the fluctuations of iron availability to the erythron in the previous weeks can be highlighted $[11,20]$.

Similar application of those technologies is being introduced by other companies (Mindray Biomedical Electronics, Nanchang, Shenzhen, China) on their analyzers [21].

\section{Reticulocytes}

Reticulocytes are immature red blood cells with a life span of only 1 to 2 days. The reticulocyte count represents an important test in the study of marrow erythropoietic activity. In clinical practice it can be used for diagnosis (distinguishing hemolytic or posthemorrhagic anemias from hypoplasticanemias), in monitoring therapy (megaloblastic anemia, iron deficiency), or as a way of checking early regeneration after marrow or stem cell transplant.

The presence of cytoplasmatic RNA is the basic difference with mature red cells which is employed for detecting this minor fraction from the RBC whole population.

The reticulocytes are classically identified by optical microscopy, using supravital stain (brillantcresyl blue, new methylene blue) that binds to ribosomal RNA. The manual/visual method of counting reticulocytes evaluates the number of reticulocytes in a total of 1000 RBCs [22].

The additional technological progress in the last 10-15 years has resulted in automated measurements of the number of reticulocytes and cellular reticulocyte parameters. Starting in the mid1990s [23], different stains binding RNA are used to distinguish reticulocytes, some fluorescence (cyanine dye, Abbott; Thiazole orange, Horiba; polymethine, Sysmex) or by absorbance (Oxazine, Siemens; new mehtylene blue, Beckman-Coulter) [8].

During the last years, flow cytometry has become the reference technique for measuring absolute reticulocyte counts and parameters of reticulocyte maturation [24,25].

Automated techniques for reticulocyte enabled the integration of reticulocyte analysis with the complete blood count in automated hematology analyzers. The advantages derived from automation are high throughput, improve precision and reliability of reticulocyte counts compared to microscope review (essentially owing to the high number of cells counted) [23],[26-28].

In summary, technological advances being incorporated into hematology analyzers since Wintrobe's days are now allowing the access to more cellular information than was ever available before through a "simple routine CBC " [29,30].

The added information contained in the "new extended hemogram" has proven its usefulness in certain clinical conditions: anemia of chronic disease, functional iron deficiency and monitoring the availability of iron during treatment with erythropoietin $[11,17],[31-40]$ thalassemia trait screening [41-43] spherocytosis $[44,45]$ iron deficiency and latent iron deficiency [46-58].

In all these clinical conditions, common in our daily practice, the added information in the contemporary hemogram aids the clinicians to make a rapid and reliable diagnosis, without additional costs. Enabling the clinician to get a prompt accurate diagnosis reduces unnecessary testing and avoids inappropriate treatment, which results in an efficient use of the resources of the Health Systems.

\section{The Promising XXI ${ }^{\mathrm{TH}}$ Century}

Current research is beginning to demonstrate that this information also has great potential to identify cellular changes that typically occur in several important medical conditions-bringing us all one step closer to using hematology analyzers as more than simple cell counters, but instead as powerful tools for the management of any medical condition that impacts the biology of blood cells.

In physiological conditions, bone marrow produces $200 * 10^{9}$ red blood cells per day; the body normally loses the same number through senescence, maintaining an overall steady state but little is known about the life cycle of 120 days of RBC.

Novel and promising research [59] has shed new light on the relationship between $\mathrm{Hb}$ content, $\mathrm{Hb}$ concentration and red cell volume. Using a systems- biology approach the dynamics of circulating red cells can be analyzed, linking the changes of volume and $\mathrm{Hb}$ concentration to red cell lifespan and removal.

The mechanisms that regulate the number, size, and hemoglobin concentration of normal red cells in circulation are not well understood. It has been established, however, that after their release from the bone marrow red cells undergo a reduction in volume and total hemoglobin content. Higgins and Mahadevan [59] used 
theory from statistical physics together with standard red cell indexes derived from electronic cell counters and the information generated by flow cytometry, to develop a master equation for the maturation and clearance of red cells. Their mathematical model implies that the total number of red cells added to the circulation equals the number removed and suggests that there is a threshold value for the MCHC below which red cells are cleared from the circulation [60]. The model distinguishes the dynamics of red cell population in healthy subjects from those of patients suffering from iron deficiency, thalassemia or anemia of chronic disease [59].

As has been exposed, manufacturers have developed fine hematology analyzers that achieve high levels of precision and accuracy in cell counting through the examination and identification of many thousands, not hundreds, of cells in each sample analyzed. In this way there are increasing amounts of data provided, which require specialist knowledge to interpret as well as to understand the limitations in the measurement of the parameter. Both laboratory scientists and clinicians need to keep up to date with new parameters and methods in hematology, implying a stronger collaboration between them. Good laboratory practice ensures that reliable results of laboratory tests are reported to the clinician [61].

The modern clinical hematology laboratory is subject to strong pressure to provide clinically relevant information that can help clinicians to make a diagnosis in a fast, cheap and useful manner, but we must not forget the words by Max Wintrobe:

"And yet, we must not stop exploring and measuring, for there is always more to learn"

Happy anniversary!

\section{References}

[1]. Wintrobe MM (1930) Classification of the anemias on the basis of differences in the size and hemoglobin content of the red corpuscles. ProcSocExpBiol Med 27:1071-1073.

[2]. Wintrobe MM (1931) The direct calculation of the volume and hemoglobin content of the erythrocyte. Am J ClinPath 1:147-149.

[3]. Wintrobe MM (1932) The size and hemoglobin content of the erythrocyte. J Lab ClinMed 17: 899-912.

[4]. Wintrobe MM (1934) Anemia: Classification and treatment on basis of differences in the average volume and hemoglobin content of the red corpuscles. Arch Int Med 54:256-280.

[5]. Greer JP, Arber DA, Glader B, List AF,Paraskevas F (2013) Clinical Hematology (13th edtn) Wolters-Kluwer Eds, Amsterdam.

[6]. Academy of Science. Biographies. http://www.nasonline.org/publications/ biographical-memoirs/memoir-pdfs/wintrobe-m-m.pdf

[7]. Wintrobe MM. Hematology (1985) the Blossoming of a Science: A Story of Inspiration and Effort. Lea \&Febiger Eds., Philadelphia.

[8]. Brugnara.C, Mohandas N (2013) Red cell indices in classification and treatment of anemias: from M.M. Wintrobes's original 1934 classification to the third millennium. CurrOpinHematol 20: 222-230.

[9]. Buttarello M Plebani M (2008) Automated Blood Cell Counts State of the art. Am J ClinPathol 130: 104-116.

[10]. Lemelson-MIT Program. Wallace A. Coulter (1913-1998): automated blood analysis. Inventor of the Week archive. http://web.mit.edu/invent/ iow/coulter.html.

[11]. Urrechaga E,BorqueL, Escanero JF (2013) Biomarkers of hypochromia: the contemporary assessment of Iron status and erythropoiesis. Biomed Research Intdoi: 10.1155/603786.

[12]. Hoffmann JJML (2012) Red cell distribution width and mortality risk ClinChimActa 413: 824-825.

[13]. Sysmex XE 5000 automated hematology AnalyserUsers Manual (2008) Chapter 11(5):11-12

[14]. Kim YR, Ornstein L (1983) Isovolumetric sphering of erythrocytes for more accurate and precise cell volume measurement by flow cytometry. Cytometry $3: 419-427$
[15]. Tycko DH, Metz MH, Epstein EA, Grinbaum (1985) A Flow-cytometric light scattering measurement of red blood cell volume and hemoglobin concentration. Appl Opt 24:1355-1365.

[16]. Brugnara C, Hipp MJ, Irving PJ, Lathrop H, Lee PA et al. (1994) Automated reticulocyte counting and measurement of reticulocyte cellular indices. Evaluation of the Miles $\mathrm{H}^{*} 3$ blood analyzer. Am J ClinPathol 102:623-632.

[17]. Ermens AAM, Hoffmann JJML, Krockenberger M, Van Wijk EM (2012) New erythrocyte and reticulocyte parameters on CELL-DYN Sapphire; analytical and preanalytical aspects. IntJnl Lab Hematol 34: 274-282.

[18]. Hoffmann JJML, van den Broek MNA, Curvers J (2012) Reference intervals of extended erythrocyte and reticulocyte parameters ClinChem Lab Med 50(5):941-948.

[19]. Urrechaga E, Borque L, Escanero JF (2009) Potential utility of the new Sysmex XE 5000 red blood cell extended parameters in the study of disorders of iron metabolism.ClinChem Lab Med 47(11): 1411-1416.

[20]. Briggs C, Longair I, Kumar P, Singh D, Machin S (2012) Performance evaluation of the Sysmexhaematology XN modular system. J ClinPathol 65(11): 1024-1030.

[21]. Jo YA, Kim MY, Kim HS, Kang HJ, Lee YK (2013) Evaluation of the Mindray BC-6800 Complete Blood Counts Analyzer. Lab Med Online / 3(3): 131-137.

[22]. Heilmeyer L(1931) Blutfarbstoffwechselstudien. Dtsch Arch Kim Med 171:123-153.

[23]. Piva E, Brugnara C, Chiandetti L, Plebani M (2010) Automated reticulocyte counting: state of the art and clinical applications in the evaluation of erythropoiesis.ClinChem Lab Med 48 (10): 369-380.

[24]. Fergusson DJ, Lee SF, Gordon PA (1990) Evaluation of reticulocyte counts by flow cytometry in a routine laboratory. Am J Hematol 33:13-17.

[25]. National Committee for Clinical laboratory Standards. Methods for reticulocyte counting (flow cytometry and supravital dyes); approved guidelines. Villanova PA: National Committee for Clinical Laboratory Standards, (1997). NCCLS documentH44-A.

[26]. Buttarello M, Bulian P, Farina G, Temporin V, Toffolo L et al. (2001) Flow Analyzers: An NCCL-SICSH Approach. Am J ClinPathol 115:100-111.

[27]. Maconi M, Danise P, Cavalca L, Formisano D (2010) Flow Cytometric Reticulocyte Counting: A Comparison Between Two Methods. J Clin Lab Anal 24: 252-255.

[28]. Chesney A, Good D, Reis M. (2011) Clinical utility of Flow Cytometry in the study of erythropoiesis and nonclonal red cell disorders In: Methods in Cell Biology Elsevier Inc. Amsterdam: 311-332.

[29]. d'Onofrio G, Chirillo R, Zini G, Caenaro G, Tommasi M, et al (1995) Simultaneous measurement of reticulocyte and red cell indices in healthy subjects and patients with microcytic and macrocytic anemia. Blood 85: 818-823.

[30]. Brugnara C (2003) Iron deficiency and erythropoiesis: New diagnostic approaches. ClinChem 49: 1573-1578.

[31]. Macdougall IC (1998) Merits of hypochromic red cells as a marker of functional iron deficiency. Nephrol Dial Transplant 13: 847-849.

[32]. Thomas C, Thomas L (2002) Biochemical markers and hematologic indices in the diagnosis of functional iron deficiency. ClinChem48: 1066-1076.

[33]. Locatelli F, Aljama P, Barany P, Canaud B, Carrera F et al. (2004) European Best Practice Guidelines Working Group. Revised European best practice guidelines for the management of anaemia in patients with chronic renal failure. Nephrol Dial Transplant 19 (suppl 2): 1-47.

[34]. Bovy C, Gothot A, Krzesinski JM, Beguin Y (2005) Mature erythrocyte indices: new markers of iron availability. Haematologica90: 549-551.

[35]. Thomas C, Kirschbaum A, Boehm D, Thomas L (2006) The diagnostic plot. Med Oncol 23(1): 23-36.

[36]. Garzia M, Di Mario A, Ferraro E, Tazza L, Rossi E et al. (2007) Reticulocyte Hemoglobin Equivalent: an indicator of reduced iron availability in chronic kidney diseases during erythropoietin therapy. Lab Haematol 13: 6-11.

[37]. Miwa N, Akiba T, Kimata N, Hamaguchi Y, Arakawa Y et al. (2010) Usefulness of measuring reticulocyte hemoglobin equivalent in the management of haemodialysis patients with iron deficiency. IntJnl Lab Hematol 32: 248255.

[38]. Buttarello M, Pajola R, Novello E, Robeschini M, Cantaro S et al. (2010) Diagnosis of iron deficiency diagnosis of iron deficiency in patients undergoing hemodialysis. Am J ClinPathol 133: 949-954.

[39]. Urrechaga E, Borque L, Escanero JF (2012) Percentage of hypochromic erythrocytes as potential marker of iron availability. ClinChem Lab Med 50(4):685-687.

[40]. Urrechaga E, Borque L, Escanero JF (2013) Erythrocyte and reticulocyte indices in the assessment of erythropoiesis activity and iron availability. IntJnl LabHematol 35:144-149.

[41]. d Onofrio G, Zini G., Ricerca BM, Mancini S, Mango G (1992) Automated measurement of red blood cell microcytosis and hypochromia in iron deficiency and beta-thalassemia trait. Arch Pathol Lab Med 116: 84-89.

[42]. Noronha JFA, Grotto HZW (2005) Measurement of reticulocyte and red blood cell indices in patients with iron deficiency anemia and $\beta$ thalassemia minor. ClinChem Lab Med 43(2): 195-197. 
[43]. Urrechaga E, Borque L, Escanero JF (2011) The role of automated measurement of red cell subpopulations in differential diagnosis of microcytic anemia and $\beta$ thalassemia screening. Am J ClinPathol 135: 374-379.

[44]. Conway AM, Vora AJ, Hinchliffe RF (2002) The clinical relevance of an isolated increase in the number of circulating hyperchromic red blood cells. J ClinPathol 55:841-844

[45]. Mullier F, Lainey E, Fenneteau O, Da Costa L, Schillinger F et al (2011) Additional erythrocytic and reticulocytic parameters helpful for diagnosis of hereditary spherocytosis: results of a multicentre study. Ann Hematol 90:759-768.

[46]. Kotisaari S, Romppanen J, Penttilä J, Punnonen K (2002) Advia 120 red blood cell and reticulocyte indices are useful in diagnosis of iron-deficiency anemia. Eur J Hematol 68: 150-156.

[47]. Buttarello M, Temporin V, Ceravolo R, Farina G, Burian P (2004) The new reticulocyte parameter RET Y of the Sysmex XE 2100. Its use in the diagnosis and monitoring of post treatment sideropenicanemia. Am J ClinPathol 121: 489-495.

[48]. Stoffman N, Brugnara C, Woods ER (2005) An algorithm using reticulocyte hemoglobin content $(\mathrm{CHr})$ measurement in screening adolescents for iron deficiency. J Adoles Health 36(6):529-533.

[49]. Ullrich C, Wu A, Armsby C, Rieber S, Wingerter S et al (2005) Screening healthy infants for iron deficiency using reticulocyte hemoglobin content. JAMA 294: 924-930.

[50]. Canals C, Remacha AF, Sarda MP, Piazuelo JM, Royo MT, et al (2005) Clinical utility of the new Sysmex XE 2100 parameter - reticulocyte hemoglobin equivalent in the diagnosis of anemia. Haematologica 90: 1133-1134.

[51]. Brugnara C, Schiller B, Moran J (2006) Ret He and assessment of iron deficient states. Clin Lab Haematol 28(5): 303-308.
[52]. Garzia M, Di Mario A, Ferraro E, Tazza L, Rossi E et al. (2007) Reticulocyte Hemoglobin Equivalent: an indicator of reduced iron availability in chronic kidney diseases during erythropoietin therapy. Lab Haematol 13: 6-11.

[53]. Ervasti M, Kotisaari S, Heinonen S, Punnonen K (2007) Use of advanced red blood cell and reticulocyte indices improves the accuracy in diagnosing iron deficiency in pregnant women at term. Eur J Hematol 79: 539-545.

[54]. Fernández R, Tubau I, Masip J, Muñoz L, Roig I et al. (2010) Low Reticulocyte hemoglobin content is associated with a higher blood transfusion rate in critically ill patients. Anesthesiology 112:1211-1215.

[55]. Prefontaine G, Darveau M, Lachance P, Drouin C, Lamarre P et al (2008) Reticulocyte hemoglobin content in 13 critically ill patients: a preliminary study. TAT 10(4): 182-188.

[56]. Ramakers C, Van der Woude DAA, Verzijl JM, Pijnenborg JMA, Van Wijk EM (2012) An added value for $\mathrm{CHr}$ and MCV in the diagnosis of iron deficiency in postpartum anemic women. IntJnl Lab Hematol 34: 510-516.

[57]. Semmelrock MJ, Raggam RB, Amrein K, Avian A, Schallmoser K et al. (2012) Reticulocyte hemoglobin content allows early and reliable detection of functional iron deficiency in blood donors. ClinChimActa 413: 678-682.

[58]. Costa O, Van Moer G, Jochmans K, Jonckheer J, Damiaens S et al. (2012) Reference values for new red blood cell and platelet parameters on the Abbott Diagnostics Cell-Dyn Sapphire. ClinChem Lab Med 50(5): 967-969.

[59]. Higgins JM, Mahadevan L (2010) Physiological and pathological population dynamics of circulating human red blood cells. PNAS 107: 20587-20592.

[60]. Weatherall DJ. System Biology and red cells (2011) N Engl J Med 364 (4): 376-377.

[61]. Briggs C (2009) Quality counts: new parameters in blood cell counting. IntJnl Lab Hem 31:277-297. 